\title{
Occurrence of violence in the elderly and its associated factors
}

\author{
A ocorrência da violência em idosos e seus fatores associados \\ La ocurrencia de violencia en ancianos y sus factores asociados
}

Paulo Henrique Silva Maia',"1,

ORCID: 0000-0001-6349-2952

Efigênia Ferreira e Ferreira"

ORCID: 0000-0002-0665-211X

Elza Machado de Melo"

ORCID: 0000-0002-3577-0721

Andréa Maria Duarte Vargas"

ORCID: 0000-0002-4371-9862

'Secretaria Municipal de Saúde. Betim, Minas Gerais, Brasil "Universidade Federal de Minas Gerais. Belo Horizonte, Minas Gerais, Brazil.

How to cite this article: Maia PHS, Ferreira EF, Melo EM, Vargas AMD. Occurrence of violence in the elderly and its associated factors. Rev Bras Enferm. 2019;72(Suppl 2):64-70. doi: http://dx.doi.org/10.1590/0034-7167-2018-0014

Corresponding Author:

Paulo Henrique Silva Maia

E-mail:caremaia@gmail.com

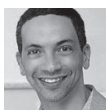

Submission: 01-26-2018

Approval: 09-23-2018

\begin{abstract}
Objective: to analyze the occurrence of violence in the elderly and its associated factors in the city of Betim, Minas Gerais. Method: cross-sectional study constituted by a population survey conducted through structured interviews. The sample was stratified by clusters and included 178 elderly people at the end. Data were analyzed by the chi-square test and was performed a Correspondence Analysis. Results: The most prevalent forms of violence were: lack of access to social rights (31\%), verbal violence $(22 \%)$, moral/psychological (19\%), lack of care $(16 \%)$, physical violence $(6 \%)$, sexual (3\%) and discrimination (3\%). Women suffered more abuse than men and violence had greater association with the degree of depressive symptoms. Conclusion: our research has direct implication for the sectors interested in coping with violence in the elderly, especially for nurses, because it shows violence is part of a cycle with characteristic associated factors that conforms a model nested mainly in the family relationship. Descriptors: Aging; Violence; Social Conditions; Nursing; Family Relations.
\end{abstract}

\section{RESUMO}

Objetivo: analisar a ocorrência da violência em idosos e seus fatores associados em Betim, Minas Gerais. Método: estudo transversal, constituído por inquérito populacional realizado através de entrevistas estruturadas. A amostra foi estratificada por conglomerados e ao final, contou com 178 idosos. Os dados foram analisados pelo teste qui-quadrado e submetidos à Análise de Correspondência. Resultados: As formas mais prevalentes de violência foram a falta de acesso a direitos sociais (31\%), a violência verbal (22\%), moral/psicológica (19\%), falta de cuidados (16\%), violência física (6\%), sexual (3\%) e discriminação (3\%). As mulheres sofreram mais abusos que os homens e houve maior associação com o grau de sintomas depressivos. Conclusão: nossa pesquisa traz implicação direta para os setores interessados no enfrentamento da violência no idoso, especialmente para os enfermeiros, pois evidencia que a violência faz parte de um ciclo com fatores associados característicos, conformando um modelo aninhado, principalmente, no relacionamento familiar.

Descritores: Envelhecimento; Violência; Condições Sociais; Enfermagem; Relacionamento Familiar.

\section{RESUMEN}

Objetivo: analizar la ocurrencia de violencia en ancianos y sus factores asociados en la ciudad de Betim, Minas Gerais. Método: estudio transversal, constituido por encuesta poblacional realizada a través de entrevistas estructuradas. La muestra fue estratificada por conglomerados y al final, hubo 178 ancianos. Los datos fueron analizados a través del test chi-cuadrado y sometidos al Análisis de Correspondencia. Resultados: Las formas más prevalentes de violencia fueron: la falta de acceso a derechos sociales (31\%), la violencia verbal (22\%), moral/psicológica (19\%), falta de cuidados (16\%), violencia física (6\%), sexual (3\%) y discriminación (3\%). Las mujeres sufrieron más abusos que los hombres y la asociación de la violencia con el grado de síntomas depresivos fue mayor. Conclusión: nuestra investigación trae implicación directa para los sectores interesados en el enfrentamiento de la violencia en el anciano, especialmente para los enfermeros, pues evidencia que la violencia es parte de un ciclo con factores asociados característicos que conforman un modelo anidado principalmente, en la relación familiar. Descriptores: Envejecimiento; Violencia; Condiciones Sociales; Enfermería; Relaciones Familiares. 


\section{INTRODUCTION}

Since the 1970s, there has been a reduction in the population growth rate worldwide with changes in age structure. The reduction in mortality and fertility rates led to this demographic trend that has been happening very fast in Brazil, compared to the European experience ${ }^{(1-2)}$. This transformation has been more marked by State medicalsanitary actions than by structural adaptations that could influence people's quality of life, and is considered a public health challenge ${ }^{(3)}$. Violence in this age group has also demanded further interventions.

Violence against the elderly is defined as a single or repeated act or omission that causes harm or distress. Mostly, it results in suffering, injury, pain, omission or loss of human rights, and reduction of quality of life ${ }^{(4)}$. The violence can be physical, verbal, moral or psychological, sexual aggression, neglect or abandonment, both social and institutional(5). This complex problem has multiple causes and devastating consequences for these individuals. In addition to aggressions to physical, mental and spiritual health, it causes poor quality of life and insecurity ${ }^{(6-7)}$.

Estimates of the prevalence of the most common types of violence among older people in high- and middle-income countries are (in descending order): financial abuse, psychological abuse, neglect, physical abuse, and sexual abuse. In Brazil, estimates of the prevalence of violence in the elderly indicate that the psychological type reaches 9.6 to $43.2 \%$, and the physical ranges from 9.6 to $67.7 \%$. Variations occur especially depending on the region of the study, sex, and functional dependence or not of the elderly person. The existing social protection mechanisms have not been sufficient to address this issue ${ }^{(8)}$.

For the World Health Organization (WHO), factors associated with violence in the elderly are part of a model with a nested hierarchy of four environmental levels, namely: individual, relationship, community and society. A study conducted in Mexico identified the following as risk factors for violence in elderly men:younger age (60-64 years), higher education (high school or higher) and low socioeconomic status. Among women, the risk was associated with depression ${ }^{(9)}$. In Brazil, the main associated factors are low educational level and cognitive factors, functional dependence and depression ${ }^{(10)}$.

The identification of factors associated with this phenomenon in the elderly population enables adequate health actions for prevention and control. Despite the considerable increase of social sensitivity with the phenomenon of violence against the elderly in Brazil, it is still difficult to estimate its magnitude in numbers. Data sources are unreliable and this fact is veiled by the family, caregivers and health service providers ${ }^{(11)}$.

Despite the undoubted evidence of national and international data on the impact of this social problem on the elderly's quality of life, health professionals'awareness of the seriousness of the situation and the important role of their area is still scarce. The identification of violence against the elderly is often neglected in health care because professionals have difficulty with detecting its indicative signals ${ }^{(11)}$. The present study addresses the role of nursing - a science that provides health care to the elderly population in various segments and contexts. This science is based on its own body of knowledge and focused on human being's integrality. Caring for the elderly is an unparalleled responsibility for nurses (at all levels of complexity), who must investigate and identify cases of violence, properly address the client, participate in multiprofessional care and intervene effectively according to each situation. In the practice focused on families and communities, preventively, nurses can apply educational strategies for the control of violence against the elderly ${ }^{(12)}$.

The focus of this study was defined based on the concern to understand the factors associated with violence against the elderly and clarify nurses' role in relation to its occurrence. The intention was to arouse these professionals'attention to the findings described herein.

\section{OBJECTIVE}

To analyze the occurrence of violence in the elderly and its associated factors in the city of Betim, state of Minas Gerais.

\section{METHOD}

\section{Ethical aspects}

This study was approved by the Research Ethics Committee of the Universidade Federal de Minas Gerais (UFMG) under number CAAE 02235212.2.0000.5149 and had the consent of the Health Secretariat of Betim. All interviewees signed two copies of the Informed Consent (IC). They kept a copy and the other was handed to interviewers.

\section{Design, place of study and period}

This is a cross-sectional study derived from a survey on health and violence prevention conducted by the Center for Health Promotion and Peace of the Department of Preventive and Social Medicine of the Faculty of Medicine, Universidade Federal de Minas Gerais (UFMG). In this study, was collected data to study the multiple facets of violence in different population groups.

The target population of the study were all people aged $\geq 60$ years residing in permanent private residences located in urban census tracts in the city of Betim, Minas Gerais. This industrial city composes the Metropolitan Region of Belo Horizonte, has 624 census tracts, 111,764 households and a population of 412,003 inhabitants at the time of data collection. The study was conducted from July to November 2014 and were investigated the episodes that occurred in the 12 months before the date of questionnaire application.

\section{Sample and inclusion and exclusion criteria}

The sample size was defined by stratified conglomerate sampling. The selection was made in three steps, namely: census tract, domicile and respondent. For the sample calculation, was adopted a confidence level of $95 \%$ and a margin of error of $1.89 \%$. The selection of census tracts and domiciles was performed electronically through the Statistical Package for Social Science (SPSS), version 20.0. For selecting the respondent subject at each home, was used the Kish methodology that recommends the random selection of a sample unit in a household.

The official list of households provided by the Institute of Geography and Statistics (Portuguese acronym: IBGE) was used and the residence address was the identifier. Refusals, non-existent addresses, closed or abandoned addresses and health conditions that prevented the performance of interviews were considered as losses. At the end, 178 elderly people participated in the study, 
which corresponded to an equal number of households. This sample was representative in the population structure of elderly people of Betim for the study of analytic prevalence.

Respondents participating in the study could be men or women, aged 60 years or more, and residing in the urban census sectors of Betim. Elderly inpatients, residents of Long Stay Institutions, who did not speak or had neurological problems did not participate in the study.

\section{Study protocol}

In this study, participants were the research group, Community Health Agents and other professionals from the Health Secretariat of Betim. The data obtained were entered in a bank built on the statistical package SPSS. All researchers were trained in a theoretical and practical way for alignment of concepts and questions based on the Researcher's Manual.

The data collection instruments were developed as questionnaires. Updated literature on the theme and the National Health Survey were adopted as reference, and previous tests were performed for adequacy. The following thematic blocks were organized: sociodemographic conditions, health, work, domestic violence, traffic violence, institutional violence, community violence and self-inflicted violence. In addition to these blocks, the elderly's health was investigated through a specific questionnaire with general questions and validated indexes, such as the Barthel index.

\section{Data and statistical analysis}

The variables were selected from the following blocks: violence (dependent variable), general information and health conditions of the elderly. From violence, were considered the place of occurrence of the aggression and the type of violence suffered (physical, verbal, moral/psychological, sexual). From the general information, were considered sex, schooling (maximum $4^{\text {th }}$ grade, and from the $5^{\text {th }}$ grade of elementary school) and marital status (with or without spouse). From health conditions, were considered the degree of depressive symptoms, independence for daily activities (Barthel Index) and degree of dependence for financial management.

An indicator was constructed based on questions about depressive symptoms in the questionnaire with the purpose of representing the degree of depressive symptoms of the elderly. For calculation of the Depressive Symptom Indicator (Portuguese acronym: ISD), the answers of 13 questions covering topics related to fear, offense, privacy, confidence, autonomy, sadness, among others were scored with negative weight. The categories of these variables were coded as yes $(1)$ and no $(-1)$, and weighted by the contribution $\left(C_{i}\right)$ and an interval ranging from more depressive symptoms $\left(C_{i}=1\right)$ to less depressive symptoms $\left(C_{i}=-1\right)$. The formula for calculation of the Depressive Symptom Indicator was the following:

$$
I S D=\sum_{i=1}^{13} X_{i}
$$

This indicator was standardized so as to assume a value on the 0-1 scale. The standardization adopted was in accordance with the equation below:

$$
I S D p a d_{\mathrm{i}}=\frac{I S D_{\mathrm{i}}-\min (I S D)}{\max (I S D)-\min (I S D)}
$$

The Barthel index, activities of daily living, was also calculated, and it enabled the evaluation of the elderly's level of dependence for performing ten basic life activities, namely: eating, personal hygiene, toilet use, bathing, dressing and undressing, control of sphincters, walking, moving from the chair to bed, climbing stairs and going down the stairs ${ }^{(10)}$. The degree of dependence for financial management was analyzed according to issues related to individual control of finances and ability to pay bills, write checks and use cards without assistance.

Initially, was performed a bivariate analysis and, later, a Correspondence Analysis (CA) to explore the structure of relations between the dependent (violence in the elderly) and independent variables. The chi-square test of homogeneity was performed to test if the proportion of violence was the same for the categories of each explanatory variable. Values below 0.05 were considered significant. The CA allows a global view of data and associations that stand out most in the graph - the closer the variables the greater the association. It is a multivariate technique of exploratory data analysis that represents the associations between the levels of the rows and columns of a contingency table with two or more entries as points in a space of reduced size. The positions of the row and column points are consistent with the table frequencies. The Correspondence Analyzes were performed in the statistical system $R$, version 3.0.2.

\section{RESULTS}

The sample included 101 elderly in the age group of 60 to 65 years, 61 elderly individuals aged 66 to 70 years, and 16 aged 70 and over. None of them lived alone at home, and no elderly with a caregiver was identified. In total, 32 cases of violence occurred, which victimized 22 elderly people, a prevalence of $11 \%$. Some elderly people suffered more than one type of violence. Of the total number of violence incidents, the following stood out: lack of access to social rights (10 elderly), verbal violence (7), moral/psychological (6), lack of necessary care (5), physical violence (2), sexual (1) and discrimination (1). The results of variables are described in Table 1.

Of the elderly who suffered violence, in $9.1 \%$ it was physical and in $4.5 \%$ it was sexual. Physical violence occurred only in the domestic environment, and among these, $11.1 \%$ were dependent elderly according to the Barthel index. Among all elderly subjects, $1.3 \%$ were dependent and suffered violence. Of the total of dependent elderly people, $20 \%$ suffered domestic violence. Most victims (88\%) were in the age range of $60-70$ years.

The correspondence map shown in Figure 1 reveals a greater association between elderly women who reported not suffering violence and not having their money used by others, whether they were dependent or independent according to the Barthel scale. Elderly women who suffered violence had a stronger association with having their money used by another person and being dependent. Elderly men who reported suffering some form of violence had more association with dependence, but had control over their own money. Elderly men who were not victims of violence had a stronger association with independence and having no one managing their money. 
Table 1 - Socioeconomic and health variables related to the occurrence of violence against the elderly, Brazil, 2014

\begin{tabular}{|c|c|c|c|c|c|c|c|}
\hline \multirow{3}{*}{ Socioeconomic and health variables } & \multicolumn{4}{|c|}{ Violence? } & & & \multirow{3}{*}{$p$ value } \\
\hline & \multirow{3}{*}{$\mathbf{n}$} & \multirow{2}{*}{ lo } & \multicolumn{2}{|c|}{ Yes } & \multicolumn{2}{|c|}{ Total } & \\
\hline & & & $\mathbf{n}$ & $\%$ & $\mathbf{n}$ & $\%$ & \\
\hline \multicolumn{7}{|l|}{ Sex } & \\
\hline Men & 62 & 35.0 & 8 & 36.4 & 70 & 35.0 & 0.1317 \\
\hline Women & 116 & 65.0 & 14 & 63.6 & 130 & 65.0 & \\
\hline \multicolumn{8}{|l|}{ Schooling } \\
\hline Up to 4 th grade of ES* & 135 & 75.9 & 15 & 68.2 & 150 & 75.0 & 0.0348 \\
\hline From 5 th grade of ES & 38 & 21.3 & 7 & 31.8 & 45 & 22.5 & \\
\hline Did not respond & 5 & 2.8 & 0 & 0.0 & 5 & 2.5 & \\
\hline \multicolumn{8}{|l|}{ Marital status } \\
\hline With spouse & 81 & 45.8 & 11 & 50.0 & 92 & 46.0 & 1.0000 \\
\hline No spouse & 97 & 54.2 & 11 & 50.0 & 108 & 54.0 & \\
\hline \multicolumn{8}{|l|}{ Financial management } \\
\hline Non-autonomous & 10 & 5.6 & 4 & 18.2 & 14 & 7.0 & 0.0002 \\
\hline Autonomous & 168 & 94.4 & 18 & 81.8 & 186 & 93.0 & \\
\hline \multicolumn{8}{|l|}{ Depressive symptoms } \\
\hline Low & 112 & 63.0 & 5 & 22.7 & 117 & 58.5 & 0.0687 \\
\hline Medium & 54 & 30.3 & 6 & 27.3 & 60 & 30.0 & \\
\hline High & 12 & 6.7 & 11 & 50.0 & 23 & 11.5 & \\
\hline \multicolumn{8}{|c|}{ Dependent on activities of daily living (Barthel index) } \\
\hline Yes & 11 & 6.2 & 3 & 13.6 & 14 & 7.0 & 0.0001 \\
\hline No & 167 & 93.8 & 19 & 86.4 & 186 & 93.0 & \\
\hline
\end{tabular}

Note: * Elementary school.

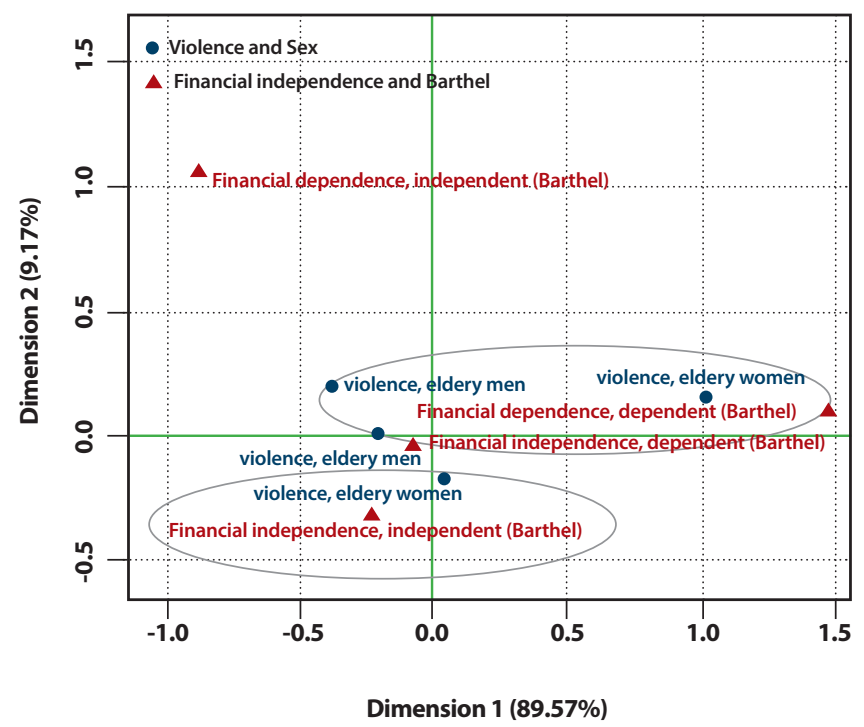

Figure 1 - Map of correspondence between violence and sex, financial independence and Barthel index

Figure 2 shows that elderly women who reported suffering violence studied from the $5^{\text {th }}$ grade of elementary school onwards and did not have a spouse. Elderly women who reported not suffering violence studied until the $4^{\text {th }}$ grade of elementary school and did not have a spouse. Elderly men who reported not suffering violence had a spouse and educational level $>4^{\text {th }}$ grade.

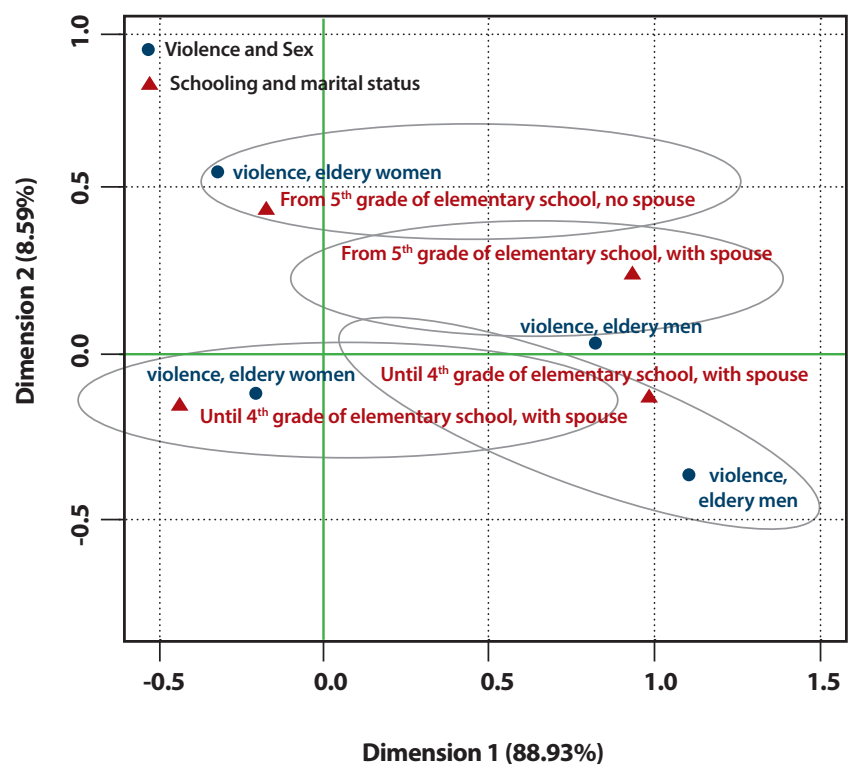

Figure 2 - Map of the correspondence between violence and sex, schooling and marital status

Figure 3 shows an association between elderly women who reported suffering violence and a high degree of depressive symptoms. Elderly women who reported not suffering violence had a medium degree of depressive symptoms. Elderly men who reported not suffering violence had a low degree of depressive symptoms. 


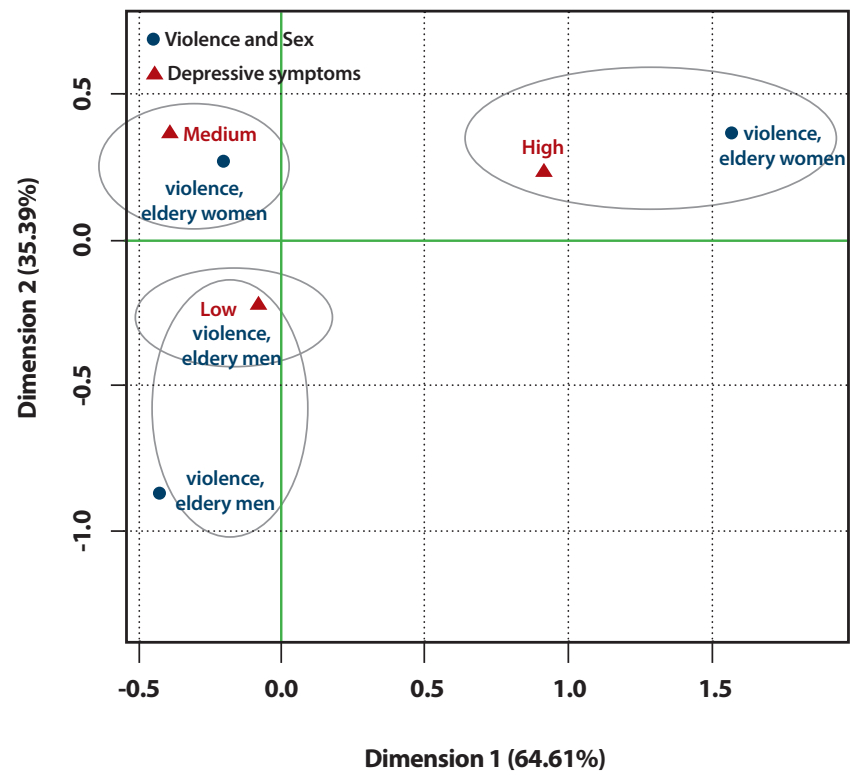

Figure 3 - Map of correspondence between violence and sex and depressive symptoms

\section{DISCUSSION}

This study represents a contribution to identify the occurrence and factors associated with violence in the elderly in a mediumsized municipality in Brazil. The analysis of results allowed to draw a profile of the victim with variation by sex. Men who suffered violence were dependent, kept control of their money and had a spouse. Women, in turn, were dependent, had no control of their money, had educational level $>4^{\text {th }}$ grade, no spouse and had more depressive symptoms.

Despite the scarcity of specific studies, the prevalence found (11.1\%) presented similar results to those of a study conducted in India ${ }^{(13)}$ in 2014. In this study, the most prevalent forms corresponded to lack of access to social rights (31\%), verbal violence (22\%), moral/psychological (19\%), lack of necessary care (16\%), physical violence (6\%), sexual (3\%) and discrimination (3\%). These rates may very likely be underestimated, considering that many people are reluctant to expose abuse ${ }^{(13-14)}$.

Domestic violence is also a major public health problem ${ }^{(14-17)}$, because it can have serious impacts on the elderly's quality of life. The psychic suffering caused leaves deep marks on the victim and on those who are close ${ }^{(14)}$. According to some authors ${ }^{(5,9,14)}$, $90 \%$ of cases of elderly abuse and neglect occur at home or in nursing homes. The results of this study are in line with national and international findings ${ }^{(9,14,17-18)}$, because they showed the direct association of the problem of domestic violence with the degree of dependence of elderly women. The condition of dependence for activities of daily living was a decisive factor for aggravation of the problem, mainly within households.

This violence can generate feelings of sadness, anger, fear, pain and suffering. In addition, these manifestations limit the decisionmaking capacity of the elderly and reduce their confidence and self-esteem ${ }^{(14,17)}$. A study on sex issues in a study on elderly abuse in Brazil and in Portugal ${ }^{(16)}$ pointed the need for new methodologies to understand and address neglect, abuse and violence against the elderly, especially in older women, suggesting that cultural factors may influence perceptions of abuse among the elderly. This is an example of a challenge for the future.

In this context, an important study variable for the outcome of violence is schooling. Studies show that education has a significant negative relationship with all types of abuse ${ }^{(13)}$. Those with more years of education are less likely to suffer violence compared to individuals with lower educational level ${ }^{(19)}$. However, the results of this study contradicted the relationship between formal education and violence, since the elderly women who studied until the " 4 th grade" had a lower chance of being victims, compared to those who studied "from the $5^{\text {th }}$ grade onwards of elementary school". This fact may be associated with the plural dimension of underreporting, highlighting the elderly person's difficulty with understanding the concept of violence and the consensus of acceptance.

When analyzing the factors associated with violence in the elderly, few studies deal with financial abuse. However, this type is equivalent to other forms of abuse, can be devastating to the elderly and is almost always directly related to family members, close friends and caregivers ${ }^{(15,20)}$. As observed in this study, the elderly women who suffered violence had their money used by another person and were more dependent according to the Barthel scale. Thus, family composition and psychosocial risk should always be investigated by health professionals, especially by nurses, as a predictor of the elderly's health.

As found in several studies ${ }^{(8,21-22)}$, the results showed that elderly women who reported suffering violence had a high degree of depressive symptoms. This determinant points to the occurrence of chronic health conditions, social isolation, emotional disturbances resulting from social issues, physiological changes and other losses ${ }^{(22)}$.

Although violence prevention depends on community awareness, crimes against the elderly are generally committed by their children or spouses ${ }^{(23)}$. The results of this study showed that elderly women with spouses had a lower incidence of violence, which was a peculiar characteristic of this study.

\section{Limitations of the study}

One limitation of this study was the use of self-reported data with consequent memory bias, mainly because participants were elderly individuals. Another important issue is that the various concepts of violence demand caution when comparing results between studies. Methodological particularities and cultural differences should be considered.

\section{Contributions to the Nursing area and public policies}

The causes of violence in the elderly are varied and many factors affect its occurrence. Several studies emphasize the importance of Nursing in this detection and prevention. Therefore, knowing the factors associated with violence can support the critical/ reflexive reasoning of nurses in elderly care. Our results clarified the nurses' role by highlighting the importance of considering physical difficulties, emotional changes, educational level and diagnosing the elderly's autonomy (financial and physical) with a view to information and prevention of violence ${ }^{(2,24)}$. 
The role of nurses is the embracement of elderly in a humanized way, also making time for a quiet conversation, and empathically, collecting as much information as possible with the guarantee of secrecy and privacy. The nursing process should avoid value judgment, indiscreet questions or treating the elderly as children. Our results also indicated the importance of paying attention to factors associated with violence in this age group, of making clinical judgment and implementing assertive and effective care. Suspected or confirmed cases of violence against the elderly must be notified.

The notification is compulsory in the health area and does not constitute a complaint, but rather a guarantee of rights. Communication to the Municipal Council of the Elderly and/or Public Prosecutor is mandatory. After the steps of elderly embracement, care and notification, social services will continue the assistance. Brazilian public policies focused on protection and prevention of violence against the elderly need to consider the factors associated with its occurrence, especially in the family environment.

\section{CONCLUSION}

This study allowed reaffirming the profile of the elderly victim of violence by analyzing its occurrence and associated factors. Financial abuse and the degree of depressive symptoms were factors strongly associated with violence in the elderly. This result demonstrates the need for attention to its occurrence and investigation.

From the perspective of research for action, the present study brings direct implication of the sectors interested in coping with violence against the elderly, especially nurses. Violence is an evident part of a cycle with characteristic associated factors included in a model nested mainly in the family relationship. Another contribution was to address the role of this professional in the care of elderly victims of violence.

Coping with violence requires intersectoral actions, and the guarantee of elderly citizens' rights is the responsibility of the state, as well as the fostering of protective measures without neglecting the role of society. Given the rapid demographic change, there is still much to be done towards improving the quality of aging in Brazil.

Academic production focused on associated factors of violence in the elderly and nurses' role is scarce, hence the direct contribution to detect violence in this age group, because were described factors strongly associated with the victimization of the elderly. The role of professional nurses was clarified as a form of coping with violence.

Our expectation is that the silence of elderly victims of violence serves to sharpen the listening of nurses and the associated factors described here trigger the detection and prevention of cases in the country. The findings of studies on violence in the elderly must support the praxis in health and offer new strategies and methods for the culture of peace and non-violence.

\section{ACKNOLEDGMENT}

Secretaria Municipal de Saúde de Betim - Minas Gerais.

\section{REFERENCES}

1. Smith AA, Silva AO, Rodrigues RAP, Moreira MASP, Nogueira JA, Tura LFR. Assessment of risk of falls in elderly living at home. Rev Latino-Am Enfermagem. 2017;25:e2754. doi: 10.1590/1518-8345.0671.2754

2. Paiva MM, Tavares DMS. Physical and psychological violence against the elderly: prevalence and associated factors. Rev Bras Enferm. 2015;68(6):727-33. doi: 10.1590/0034-7167.2015680606i

3. Mendes EV. As redes de atenção à saúde. Ciênc Saúde Colet. 2010;15(5):2297-305. doi: 10.1590/S1413-81232010000500005

4. Silva CFS, Dias CMSB. Violência contra idosos na família: motivações, sentimentos e necessidades do agressor. Psicol Ciênc Prof. 2016;36(3):637-52. doi: 10.1590/1982-3703001462014

5. Baker MW. Elder mistreatment: risk, vulnerability, and early mortality. J Am Psychiatr Nurses Assoc. 2007;12(6):313-21. doi: $10.1177 / 1078390306297519$

6. Santos CM, Marchi RJ, Martins AB, Hugo FN, Padilha DMP, Hilgert JB. The prevalence of elder abuse in the Porto Alegre metropolitan area. Braz Oral Res. 2013;27(3):197-202. doi: 10.1590/S1806-83242013005000011

7. Netuveli G, Wiggins RD, Hildon Z, Montgomery SM, Blane D. Quality of life at older ages: evidence from the English longitudinal study of aging (wave 1). J Epidemiol Community Health. 2006;60(4):357-63. doi: 10.1136/jech.2005.040071

8. Bolsoni CC, Coelho EBS, Giehl MWC, D'Orsi E. Prevalence of violence against the elderly and associated factors - a population based study in Florianópolis, Santa Catarina. Rev Bras Geriatr Gerontol. 2016;19(4):671-82. doi: 10.1590/1809-98232016019.150184

9. Ruelas-González MG, Duarte-Goméz MB, Flores-Hernández S, Ortega-Altamirano DV, Cortés-Gil JD, Taboada A, et al. Prevalence and factors associated with violence and abuse of older adults in Mexico's 2012 National Health and Nutrition Survey. Int J Equity Health. 2016;15:35. doi: 10.1186/s12939-016-0315-y

10. Dong X, Simon MA. Vulnerability risk index profile for elder abuse in a community-dwelling population. J Am Geriatr Soc. 2014;62(1):10-5. doi: $10.1111 /$ jgs.12621

11. Souza ER, Minayo MCS. The insertion of the violence against elderly theme at health care public policies in Brazil. Ciênc Saúde Colet. 2010;15(6):2659-68. doi: 10.1590/S1413-81232010000600002

12. Rodrigues IS, Feitosa CDA, Guimarães DBO, Mendes PN, Figueiredo MLF, et al. Violence against the elderly in health research: an integrative review. Rev Enferm UFPE On Line. 2015;9(3):7126-32. doi: 10.5205/reuol.7505-65182-1-RV.0903201515 
13. Skirbekk V, James KS. Abuse against elderly in India - The role of education. BMC Public Health. 2014;14:336. doi: 10.1186/1471-2458-14-336

14. Souto RQ, Merighi MAB, Guruge MS, Jesus MCP. Older Brazilian women's experience of psychological domestic violence: a social phenomenological study. Int J Equity Health. 2015;14:44. doi: 10.1186/s12939-015-0173-z

15. Brownell P. Preventing neglect, abuse and violence against older women. Global Cooperation Newsletter, October Issue. Entebbe: International Council of Social Welfare; 2013.

16. Brownell P. A reflection on gender issues in elder abuse research: Brazil and Portugal. Ciênc Saúde Colet. 2016;21(11):3323-30. doi: $10.1590 / 1413-812320152111.23142016$

17. Minayo MCS, Souza ER, Paula DR. Revisão sistemática da produção acadêmica brasileira sobre causas externas e violências contra a pessoa idosa. Ciênc Saúde Colet. 2010;15(6):2719-28. doi: 10.1590/S1413-81232010000600010

18. Dong $X$, Simon MA. A descriptive study of sex differences in psychosocial factors and elder mistreatment in a Chinese community population. Int J Gerontol. 2008;2(4):206-14. doi: 10.1016/S1873-9598(09)70009-2

19. Melchiorre MG, Di Rosa M, Lamura G, Torres-Gonzales F, Lindert J, Stankunas M, et al. Abuse of older men in seven European countries: a multilevel approach in the framework of an ecological model. PLoS ONE. 2016;11(1):e0146425. doi: 10.1371/journal.pone.0146425

20. Ferrari AJ, Somerville AJ, Baxter AJ, Norman R, Patten SB, Vos T, et al. Global variation in the prevalence and incidence of major depressive disorder: a systematic review of the epidemiological literature. Psychol Med. 2013;43(3):471-81. doi: 10.1017/S0033291712001511

21. Fazel S, Wolf A, Chang Z, Larsson H, Goodwin GM, Lichtenstein P. Depression and violence: a Swedish population study. Lancet Psychiatry. 2015;2(3):224-32. doi: 10.1016/S2215-0366(14)00128-X

22. Lopes LE, Oliveira MLC. Violence against women: systematic review of the Brazilian scientific literature within the period from 2009 to 2013. Ciênc Saúde Colet. 2015;20(11):3523-32. doi: 10.1590/1413-812320152011.11302014

23. Corbi G, Grattagliano I, Ivshina E, Ferrara N, Cipriano AS, Campobasso CP. Elderly abuse: risk factors and nursing role. Intern Emerg Med. 2015;10(3):297-303. doi: 10.1007/s11739-014-1126-z

24. Oliveira KSM, Carvalho FPB, Oliveira LC, Simpson CA, Silva FTL, Martins AGC. Violence against the elderly: the conceptions of nursing professionals regarding detection and prevention. Rev Gaúcha Enferm. 2018;39:e57462. doi: 10.1590/1983-1447.2018.57462 